included nucleolus type $(0.88 \%)$, centromere type (3.54\%), cytoplasm type $(7.96 \%)$, homogeneity $(29.20 \%)$ and granularity $(58.41 \%)$. Also, there was no significant difference in plasma Lp-PLA2 level between different karyotypes $(p=0.153)$. The average level of ACA was $12.88 \pm 23.87 \mathrm{RU} / \mathrm{ml}$ and there was no significant correlation between plasma Lp-PLA2 level and ACA level $(p=0.839)$ Anti- $\beta 2 \mathrm{GP} 1$ antibodies were classified as negative $(<20 \mathrm{U} / \mathrm{ml}, 91.48 \%)$ and positive $(\geq 20 \mathrm{U} / \mathrm{ml}, 8.52 \%)$. Plasma Lp-PLA2 level did not differ significantly between anti- $\beta 2 \mathrm{GP} 1$ antibody negative and positive patients $(\mathrm{p}=0.449)$. Lupus anticoagulant PT-IgG and PT-IgM were classified as negative $(<18 \mathrm{U} / \mathrm{ml})$ and positive $(>18 \mathrm{U} / \mathrm{ml})$. PT-IgM were all negative and there was no significant difference in plasma Lp-PLA2 level between PT-IgG negative $(96.59 \%)$ and positive $(3.41 \%)$ patients $(\mathrm{p}=0.279)$.

Conclusions: Plasma Lp-PLA2 level in patients with connective tissue disease have no significant correlation with age, gender, ANA titer, karyotype, ACA, anti- $\beta$ 2GP1 antibody and LA. The role of plasma Lp-PLA2 in connective tissue disease may be different from APL-Ab.

Disclosure of Interest: None declared

DOI: 10.1136/annrheumdis-2018-eular.4539

\section{AB0610 $\quad$ CORRELATION BETWEEN TRADITIONAL CARDIOVASCULAR RISK INDEXES AND ARTERIAL STIFFNESS IN PATIENTS WITH GENERALISED LUPUS ERYTHEMATOSUS}

M. Vázquez-Del Mercado ${ }^{1,2}$, A. Llamas Garcia ${ }^{1}$, A. Coldivar-Gabriel ${ }^{2}$, E. GomezBañuelos $^{1}$, D.A. Victoria-Rios ${ }^{1}$, J.I. Lopez-Blasi ${ }^{1}$, K.I. Arrona-Rios ${ }^{1}$, F.D.J. PerezVazquez ${ }^{2}$, G. Diaz-Rubio ${ }^{2}$, F. Grover-Páez ${ }^{3}$. ${ }^{1}$ Servicio de Reumatología 004086 PNPC CONACYT, Hospital Civil de Guadalajara Dr. Juan I. Menchaca; ${ }^{2}$ Instituto de Investigación en Reumatología y del Sistema Músculo Esquelético; ${ }^{3}$ Instituto de Terapéutica Experimental y Clínica, Universidad de Guadalajara, Guadalajara, Mexico

Background: Cardiovascular disease (CVD) is the leading cause of late death in patients with systemic lupus erythematosus (SLE). SLE is related with up to 50 fold risk of CVD. SLE is recognised as an independent cardiovascular risk factor (CVR). However, traditional scales underestimates the CVR in SLE.

Objectives: Determine the correlation between traditional CVR scores (Framingham, systematic coronary risk evaluation (SCORE), arteriosclerotic cardiovascular disease (ASCVD) and arterial stiffness (AS) in an open population of SLE, assessing AS by pulse wave velocity (PWV), vascular damage through cardioankle vascular index (CAVI), ankle-brachial index ( $\mathrm{ABI})$, quality intima media thickness (qIMT) and SLE disease activity using the systemic lupus erythematosus disease activity index (SLEDAI) and systemic lupus international collaborating clinics (SLICC).

Methods: Patients with SLE of 18 years old and older, diagnosed according to SLICC 2012 criteria. Informed written consent. AS was determined by PWV, CAVI, ABI, and qIMT. Disease activity was recorded by SLEDAI and SLICC. Comparison between qualitative variables will be done through the X2 test or the Fisher exact test. For comparison of the quantitative variables with normal distribution Student's T and ANOVA tests were done. The correlation coefficient $(r)$ of Pearson was calculated. Variables with a $p \leq 0.2$ value were included in a multiple linear regression model to evaluate the influence of the disease variables on CVR. SPSS v.22 software (IBM, inc) and the Graphpad V software were used.

Results: The total of SLE patient were $44(100 \%)$, with a mean age of $34 \pm 12$ years old. Thirty six women $(82 \%)$. The mean evolution time was $6 \pm 5$ years. Smoke was registered in $16 \%$ ( 7 cases). Systolic blood pressure $110 \pm 14$, diastolic

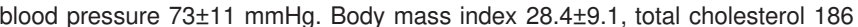
\pm 47 , triglycerides $143 \pm 67, \mathrm{cHDL} 42.9 \pm 5.1, \mathrm{cLDL} 57 \pm 27 \mathrm{mg} / \mathrm{dL}$. Erythrocyte sedimentation rate of $17 \pm 14 \mathrm{~mm} / \mathrm{hr}$, cReactive protein $7.1 \pm 4.8 \mathrm{mg} / \mathrm{L}$. Anti.dsDNA antibodies were present in $47.7 \%$ of the cases. ${ }^{21}$ Secondary antiphospholipid syndrome in $13.6 \% .^{6}$ Mean SLEDAI 8 (range 0-32), mean SLICC 1 (range 0-6). C3 levels $83.6 \pm 21.4, \mathrm{C} 419.5 \pm 18.8 \mathrm{mg} / \mathrm{dL}$. The most important correlations found were with qIMT and age 0.651 (<0.001), BMI 0.513 ( p 0.001), cRp 0.351 (0.033), cLDL 0.400 (0.01). Framingham score was able to predict CVR up to $44.8 \%$ the measurement of PWV, ASCVD in $30 \%$ and SCORE up to $22 \%$.

Conclusions: Traditional scores (Framingham, SCORE, ASCVD) underestimate cardiovascular risk in patients with SLE. The most important finding is that qIMT was able to correlate more than age, to BMI and cLDL in SLE patients.
Disclosure of Interest: None declared

DOI: 10.1136/annrheumdis-2018-eular.7409

\section{AB0611 DISEASE ACTIVITY AND ORGAN DAMAGE IN PATIENT WITH CHILDHOOD-ONSET SYSTEMIC LUPUS ERYTHEMATOSUS, FROM CHILDHOOD TO ADULTHOOD: A RETROSPECTIVE STUDY OVER THE LAST 25 YEARS}

E. Hosticka ${ }^{1}$, M. Novoselec ${ }^{1}$, M. Sestan ${ }^{1}$, N. Cekada ${ }^{1}$, M. Frkovic ${ }^{1}$, I. Padjen ${ }^{2}$, M. Sentic ${ }^{2}$, B. Anic ${ }^{2}$, M. Jelusic ${ }^{1} .{ }^{1}$ Department of Paediatrics; ${ }^{2}$ Department of Internal Medicine, University Hospital Centre Zagreb, University of Zagreb School of Medicine, Zagreb, Croatia

Background: Although clinical symptoms and immunological findings are common in both children and adults with systemic lupus erythematosus (SLE), children generally have a more severe clinical presentation at the time of diagnosis with a larger number of affected organs, a much more aggressive clinical course and greater chance of developing organ damage over time.

Objectives: To compare the SLEDAI-2K disease activity index in patients with SLE at the time of diagnosis with SLEDAI-2K in the same patients in adulthood and to compare of the SLICC/ACR damage index (SDI) in patients with CSLE at the last follow up in childhood with SLICC/ACR of the same patients in adulthood. Methods: This retrospective study included children who were diagnosed with CSLE, according to the ACR 1997 and SLICC 2012 criteria, in the period from 1991-2016 at the Referral Centre for Paediatric and Adolescent Rheumatology Republic of Croatia, Department of Paediatrics, University Hospital Centre Zagreb and who by the end of March 2017 reached the age of majority at 18 and continued their treatment at the Department of Internal Medicine, University Hospital Centre Zagreb.

Results: Out of 95 children with cSLE, 48 patients (42 females and 6 males) who attained the age of majority, were included in the study. Mean age at the time of diagnosis was 13.5 years (range 6-18), and the mean disease duration was 11 years. Mean SLEDAI-2K was 19,25 (range 0-42) in childhood and 7125 (range $0-30$ ) in adulthood. In adulthood, thirty-two patients $(66.67 \%)$ showed improvement, three $(6.25 \%)$ disease progression, six $(12.5 \%)$ had the same disease activity and seven patients (14.58\%) were in remission. 13 children $(27 \%)$ had organ damage at the last follow up with mean SDI $0.43(0-6)$ and 20 patients in adulthood $(41,67 \%)$ had organ damage with SDI $0.75(0-6)$. Cataract, erosive arthritis and avascular necrosis were the most common organ damage in both groups. The most common presenting symptoms in childhood were musculoskeletal (predominantly arthritis) occurring in 34 children $(70.83 \%)$, mucocutaneous (rash) noted in $31(64.58 \%)$ and fever in 21 patients $(43.75 \%)$. Of different laboratory tests the most common were positive antinuclear antibodies (ANA) screen (95.83\%) and hypocomplementaemia (75\%). Proteinuria was noticed in 26 children $(54.17 \%)$. Similarly, in adulthood the most common symptoms were arthritis in $10(20.83 \%)$ and rash in 8 patients $(16.67 \%)$. Alopecia, headaches and visual disturbances were represented with $12.5 \%$ each. ANA screen was positive in 27 patients $(56.25 \%)$ and hypocomplementaemia present in 22 patients $(45.83 \%)$. Conclusions: At the time of diagnosis in childhood, disease activity is very high while in adulthood there is a significant decrease in disease activity. Higher disease activity in childhood is related to the development of the organ damage in adulthood.

\section{REFERENCES:}

[1] Couture J, Silverman ED. Update on the pathogenesis and treatment of childhood-onset systemic lupus erythematosus. Curr Opin Rheumatol. 2016;28:488-96

[2] Brunner HI, Silverman ED, To T, et al. Risk factors for damage in childhood-onset systemic lupus erythematosus: cumulative disease activity and medication use predict disease damage. Arthritis Rheum. 2002;46:436-44

Disclosure of Interest: None declared

DOI: 10.1136/annrheumdis-2018-eular.4567 